\title{
Impact of hydrogen injection on thermophysical properties and measurement reliability in natural gas networks
}

\author{
Marco Dell'Isola, Giorgio Ficco, Linda Moretti *, Alessandra Perna, Daniele Candelaresi, \\ Giuseppe Spazzafumo
}

Department of Civil and Mechanical Engineering, University of Cassino and Southern Lazio, Cassino, Italy;

\begin{abstract}
In the context of the European decarbonization strategy, hydrogen is a key energy carrier in the medium to long term. The main advantages deriving from a greater penetration of hydrogen into the energy mix consist in its intrinsic characteristics of flexibility and integrability with alternative technologies for the production and consumption of energy. In particular, hydrogen allows to: i) decarbonise end uses, since it is a zero-emission energy carrier and can be produced with processes characterized by the absence of greenhouse gases emissions (e.g. water electrolysis); ii) help to balancing electricity grid supporting the integration of non-programmable renewable energy sources; iii) exploit the natural gas transmission and distribution networks as storage systems in overproduction periods. However, the hydrogen injection into the natural gas infrastructures directly influences thermophysical properties of the gas mixture itself, such as density, calorific value, Wobbe index, speed of sound, etc [1]. The change of the thermophysical properties of gaseous mixture, in turn, directly affects the end use service in terms of efficiency and safety as well as the metrological performance and reliability of the volume and gas quality measurement systems. In this paper, the authors present the results of a study about the impact of hydrogen injection on the properties of the natural gas mixture. In detail, the changes of the thermodynamic properties of the gaseous mixtures with different hydrogen content have been analysed. Moreover, the theoretical effects of the aforementioned variations on the accuracy of the compressibility factor measurement have been also assessed.
\end{abstract}

\section{Introduction}

The increasing penetration of non-programmable renewable energy sources (RES) (e.g. photovoltaic and wind) in electricity generation is impacting considerably on the power grid management system. Owing to the intermittent and random nature, power production from non-programmable RES generates critical issues in the balance between energy supply and demand, especially during overgeneration periods. Such issues can be tackled by employing large storage capacities, which are still not guaranteed by the storage systems installed on the electricity grid.

Currently, Power to Gas (PtG) represents the most suitable technology for storing excess electricity produced by non-programmable RES providing flexibility to the electrical system

\footnotetext{
*Corresponding author: linda.moretti@unicas.it
} 
[2]. Exploiting the natural gas (NG) transmission and distribution networks, as well as the storage features of the existing NG infrastructure, the hydrogen produced from surplus renewable energy can be injected into the NG pipeline system allowing to store large amounts of energy on large-scale and for long-term period [3]. This will allow to decarbonize end-use sectors (e.g., buildings, transport, industry), since it is a zero-emission energy carrier, in addition to offer balancing and regulation services to the power grid. Blending hydrogen into the existing natural gas pipeline network is therefore a promising perspective for facilitating the development of an energy system based on a high share of non-programmable RES.

Nevertheless, the reliability of injection of hydrogen in natural gas (H2NG) mixtures into existing infrastructures (e.g. pipelines, valves, compressor, boilers, measuring systems) is still a debated research topic. Indeed, increasing hydrogen content in NG lead to significant changes in thermo-physical properties of the resulting mixture. Stetsenko et al. [1] investigated how thermo-physical properties of different gas types of the " $\mathrm{H}$ " group of EN 437:2019 change with increasing hydrogen fraction. The authors have proved that all tested gases remain in group " $\mathrm{H}$ " when hydrogen is injected into natural gas with a content ranging from $2 \%$ to $23 \%$. In detail, the properties of the mixtures vary as follows: i) the density (relative density) decreases in the range $1.7-20.5 \%$; ii) the higher heating value decreases in the range $1.4-16 \%$; iii) the Wobbe Index decreases in the range $0.49-5.7 \%$; iv) the sound speed increases in the range $1-13.5 \%$. The change of the thermodynamic properties leads to combustion and calorific characteristics changes. This could result in safety issues related to the volumetric percentage of hydrogen added (e.g. fugitive emissions are larger with hydrogen, flammability limits of hydrogen are wider than methane) [4]. Generally, only minor criticalities occur with blends of less than $5-15 \%$ hydrogen by volume, depending on site specific conditions and natural gas mixture compositions. Extensive studies and tests about the existing pipeline, valves, compressor, measuring systems and end-use appliances must be addressed for higher volume fractions of hydrogen in the range of $15-50 \%$ issues [5].

Several studies have investigated the $\mathrm{H} 2 \mathrm{NG}$ mixtures effects on the reliability of existing measurement systems. Stetsenko et al. [1] demonstrated that the injection of more than $10 \%$ hydrogen to natural gas allows to manage existing gas transportation and gas consumption systems without the need for reconstructions, modifications, changes in the algorithms for calculating physical parameters of the gas mixture and volumetric flow rate. On the other hands, further studies and the development of new algorithms are needed for higher hydrogen contents. In [6] no problems were recorded relating to the materials used in the construction of ultrasonic, membrane and turbine gas meters for hydrogen up to $30 \%$. In particular, diaphragm, turbine and ultrasonic gas meters should be insensitive to this effect. However, they encourage field tests to determine the measurement accuracy of gas meters with H2NG mixtures, as well as long-term metrological stability. Iskov et al. [7] analysed the mediumterm effects (about one year) of 100\% hydrogen on the metrological properties of traditional turbine, rotary piston and diaphragm gas meters at a pressure of $20 \mathrm{mbar}$, finding that hydrogen had no effect on the metrological characteristics of the gas meters tested, despite some issues with the turbine meter seal. Dehaeseleer [8] demonstrated that there are no operational issues with traditional gas meters (turbine, rotary piston and diaphragm) up to $10 \%$ of the hydrogen content in natural gas, however, above this value a new calibration could be necessary, together with the evaluation of changes to the design of the meters. Jaworski [9] experimentally evaluated the durability of diaphragm gas meters with hydrogen, demonstrating they are not significantly affected by injection of hydrogen up to $15 \%$. The long-term drift has also been related to the wear of the internal parts of the meter, rather than to the hydrogen content in the gas mixture. In addition, no damage was found that could represent a threat to operational safety as all gas meters tested maintained unaltered tightness during and after the test. Jaworski and Dudek [10] found capillary thermal mass gas meters 
comply with accuracy limits and only occasional values exceed the maximum permissible errors (MPE) for H2NG with 2, 4 and 5\% of hydrogen; on the other hand, with hydrogen content of 10 and $15 \%$ they significantly exceeded the MPEs with error curves systematically shifted towards negative errors. No experimental evidences are available in the literature against the injection of $\mathrm{H}_{2}$ up to $10 \%$ for ultrasonic meters, whereas for higher levels further experimental research is required [11].

Finally, as regards the effects on the volume conversion, Lach [12] investigated the effects of $\mathrm{H} 2 \mathrm{NG}$ on the calculation of the compressibility factor. To this end, tests were carried out in the laboratory of the Polish National Research Oil and Gas Institute to compare SGERG88 and AGA8-DC92 methods to determine the compressibility coefficient of gas with an increasing hydrogen content. In fact, both methods have application limitations in terms of hydrogen content in natural gas up to $10 \%(\mathrm{~mol} / \mathrm{mol})$. Research has shown that the AGA8DC92 method provides satisfactory results when the hydrogen content is less than $40 \%$ ( $\mathrm{mol} / \mathrm{mol})$.

This paper is aimed at presenting the results of a comprehensive study on the effects of hydrogen injection on the thermodynamic properties of the natural gas mixture. The main thermo-physical parameters of NG mixtures, including density, relative density, higher heating value, Wobbe Index, specific heat capacity and sound speed have been investigated. Furthermore, in order to assess the reliability of measurement systems installed on existing gas infrastructures, the impact of hydrogen injection on the accuracy of the compressibility factor measurement have been evaluated.

\section{Methods}

\subsection{Calculation of the thermodynamic properties}

The density of the real gaseous mixture at metering reference conditions is obtained using the ISO 6976:2016 [13] formula:

$$
D(p, t)=\frac{D^{0}}{Z(p, t)}
$$

where : i) $Z(\mathrm{p}, t)$ is the compressibility factor of the gaseous mixture calculated in accordance with the ISO $6976: 2016$ [13]; ii) $\mathrm{D}^{0}$ is the density of the ideal gas at the metering reference conditions evaluated through the following equation:

$$
D^{0}(p, t)=\frac{M}{V^{0}}
$$

where: i) $\mathrm{V}^{0}$ is the ideal molar volume of the mixture calculated according to the ideal gas law; ii) $\mathrm{M}$ is the molar mass of the gas mixture calculated from:

$$
M=\sum_{j=1}^{N} x_{j} M_{j}
$$

where: i) $x_{j}$ is the mole fraction of the $\mathrm{j}$-th component in the gas mixture; ii) $M_{j}$ is the molar mass of the $\mathrm{j}$-th component.

The relative density is defined as the ratio of the density of the gas mixture to the density of dry air of reference composition at the same specified conditions of pressure and temperature. 
It has been calculated according to the ISO 6976:2016 formula for the real gaseous mixture [13]:

$$
G(t, p)=\frac{G^{0} \cdot Z_{\text {air }}(t, p)}{Z(t, p)}
$$

where: i) $Z(p, \mathrm{t})$ is the compressibility factor of the gaseous mixture calculated in accordance with the ISO 6976:2016 [13]; ii) $Z_{\text {air }}(p, \mathrm{t})$ is the compressibility factor of dry air of reference composition; iii) $G^{0}$ is the relative density of the ideal gas, which is calculated through the following formula:

$$
G^{0}=\sum_{j=1}^{N} x_{j} \frac{M_{j}}{M_{a i r}}
$$

where: i) $x_{j}$ is the mole fraction of the $\mathrm{j}$-th component in the gas mixture; ii) $\mathrm{M}_{\mathrm{j}}$ is the molar mass of the $\mathrm{j}$-th component; iii) $\mathrm{M}_{\text {air }}$ is the molar mass of dry air of reference composition.

The calculation of the ideal higher heating value $(\mathrm{Hv})_{G}^{0}$ on volume basis, at a temperature $t_{1}$, has been carried out basing on the ISO 6976:2016 standard [13] through the following equation:

$$
(H v)_{G}^{0}(t, p)=\frac{(H c)_{G}^{0}(t)}{V^{0}}
$$

where: i) $(H c)_{G}^{0}(t)$ is the ideal higher molar-basis calorific value; ii) $V^{0}$ is the ideal molar volume of the mixture calculated according to the ideal gas law.

The Wobbe Index is defined in accordance with ISO 6976:2016 [13] as the ratio of the higher heating value, at specified reference condition, to the square root of the relative density:

$$
W_{G}^{0}(t, p)=\frac{(H v)_{G}^{0}(t, p)}{\sqrt{G^{0}}}
$$

where: i) $(\mathrm{Hv})_{G}^{0}$ is the higher heating value on volume basis of the ideal mixture; ii) $\mathrm{G}^{0}$ is the relative density the ideal mixture.

A crucial parameter for ultrasonic gas meters accuracy is represented by the speed of sound, which can be estimated through the AGA 10 formula [14]:

$$
\mathrm{u}=18.591\left(\frac{T \cdot Z \cdot k}{\rho_{s}}\right)^{0.5}
$$

where: i) $T$ is the absolute temperature; ii) $Z$ is the compressibility factor of the gaseous mixture calculated employing the ISO 6976:2016 standard [13]; iii) $k$ is the adiabatic coefficient of gas mixture (i.e. the ratio between heat capacities at constant pressure and volume, respectively); iv) $\rho_{s}$ is the density of the gas mixture at reference conditions.

On the other hand, the product $D \cdot c_{p}$ strongly affects thermal mass gas meters. The correlations depending on temperature and gaseous mixture composition available in literature can be employed estimate to the specific heat capacity variation as a function of the hydrogen content. The specific heat capacity at constant pressure has been evaluated as the 
weighted average of the specific heat capacities at constant pressure of the components constituting the gaseous mixture:

$$
c_{p}\left(t_{1}\right)=\sum_{j=1}^{N} x_{j} \cdot c_{p, j}
$$

where: i) $x_{j}$ is the mass fraction of the $\mathrm{j}$-th component in the gas mixture; ii) $c_{p, j}$ is the specific heat capacity at constant pressure of the $j$-th component calculated according to the equation in [15]:

$$
c_{p, j}(T)=A_{j}+B_{j} T+C_{j} T^{2}+D_{j} T^{3}+E_{j} T^{4}
$$

where i) $T$ is the absolute temperature; ii) $A_{j}, B_{j}, C_{j}, D_{j}, E_{j}$ are the regression coefficients for the $\mathrm{j}$-th component of the gaseous mixture (see Table 1).

Table 1. Regression coefficients for chemical compound [16].

\begin{tabular}{|l|c|c|c|c|c|c|}
\hline \multicolumn{1}{|c|}{ Component } & $\begin{array}{c}\text { Temperature } \\
\text { range [K] }\end{array}$ & $\mathbf{A}$ & $\mathbf{B}$ & $\mathbf{C}$ & D & E \\
\hline Methane, $\mathrm{CH}_{4}$ & $50-1500$ & 34.942 & $-3.9957 \mathrm{E}-02$ & $1.9184 \mathrm{E}-04$ & $-1.5303 \mathrm{E}-07$ & $3.9321 \mathrm{E}-11$ \\
\hline Ethane, $\mathrm{C}_{2} \mathrm{H}_{6}$ & $100-1500$ & 28.146 & $4.3447 \mathrm{E}-02$ & $1.8946 \mathrm{E}-04$ & $-1.9082 \mathrm{E}-07$ & $5.3349 \mathrm{E}-11$ \\
\hline Propane, $\mathrm{C}_{3} \mathrm{H}_{8}$ & $200-1000$ & 31.986 & $4.27 \mathrm{E}-02$ & $5.00 \mathrm{E}-04$ & $-6.56 \mathrm{E}-07$ & $2.56 \mathrm{E}-10$ \\
\hline n-Butane, $\mathrm{n}-\mathrm{C}_{4} \mathrm{H}_{10}$ & $200-1500$ & 20.056 & $2.8153 \mathrm{E}-01$ & $-1.3143 \mathrm{E}-05$ & $-9.4571 \mathrm{E}-08$ & $3.4149 \mathrm{E}-11$ \\
\hline iso-Butane, iso- $_{4} \mathrm{H}_{10}$ & $200-1500$ & 6.772 & $3.1447 \mathrm{E}-01$ & $-1.0271 \mathrm{E}-04$ & $-3.6849 \mathrm{E}-08$ & $2.0429 \mathrm{E}-11$ \\
\hline n-Pentane, $\mathrm{n}-\mathrm{C}_{5} \mathrm{H}_{12}$ & $200-1500$ & 26.671 & $3.2324 \mathrm{E}-01$ & $4.2820 \mathrm{E}-05$ & $-1.6639 \mathrm{E}-07$ & $5.6036 \mathrm{E}-11$ \\
\hline iso-Pentane, iso- $_{5} \mathrm{H}_{12}$ & $200-1000$ & 16.288 & $3.1754 \mathrm{E}-01$ & $2.0237 \mathrm{E}-04$ & $-4.3027 \mathrm{E}-07$ & $1.8001 \mathrm{E}-10$ \\
\hline n-Hexane, $\mathrm{C}_{6} \mathrm{H}_{14}$ & $200-1500$ & 25.924 & $4.1927 \mathrm{E}-01$ & $-1.2491 \mathrm{E}-05$ & $-1.5592 \mathrm{E}-07$ & $5.8784 \mathrm{E}-11$ \\
\hline Nitrogen, $\mathrm{N}_{2}$ & $50-1500$ & 29.342 & $-3.5395 \mathrm{E}-03$ & $1.0076 \mathrm{E}-05$ & $-4.3116 \mathrm{E}-09$ & $2.5935 \mathrm{E}-13$ \\
\hline Carbon dioxide, $\mathrm{CO}_{2}$ & $50-5000$ & 27.437 & $4.2315 \mathrm{E}-02$ & $-1.9555 \mathrm{E}-05$ & $3.9968 \mathrm{E}-09$ & $-2.9872 \mathrm{E}-13$ \\
\hline Hydrogen, $\mathrm{H}_{2}$ & $250-1500$ & 25.399 & $2.0178 \mathrm{E}-02$ & $-3.8549 \mathrm{E}-05$ & $3.1880 \mathrm{E}-08$ & $-8.7585 \mathrm{E}-12$ \\
\hline
\end{tabular}

\subsection{Calculation of the compressibility factor}

The compressibility factor at metering conditions, $\mathrm{Z}$, has been estimated basing on the ISO 12213-2:2010 [17]. The latter uses the AGA8-DC92 equation, developed by Starling e Savidge in 1992 [18]. The equation is an extended virial-type formulation and, which is only capable to calculate the properties in the gas phase. Moreover, it employs a detailed molarcomposition in which all constituents present in amounts exceeding a mole fraction of 0.00005 should be represented. It may be written as:

$$
\mathrm{Z}=1+B \rho_{m}-\rho_{r} \sum_{n=13}^{18} C_{n}^{*}+\sum_{n=13}^{58} C_{n}^{*}\left(b_{n}-c_{n} k_{n} \rho_{r}^{k_{n}}\right) \rho_{r}^{k_{n}} \exp \left(-c_{n} \rho_{r}^{k_{n}}\right)
$$

where: i) B is the second virial coefficient; ii) $\rho_{m}$ is the molar density; iii) $\rho_{r}$ is the reduced density; iv) $b_{n}, c_{n}, k_{n}$ are constants; v) $C_{n}^{*}$ are the coefficient which depend on the temperature and NG mixture composition. The reduced density $\rho_{r}$ is correlated to the molar density $\rho_{m}$ through the below relation:

$$
\rho_{r}=K^{3} \rho_{m}
$$

where: i) $\mathrm{K}$ is a mixture size coefficient; ii) $\rho_{m}$ is the molar density calculated using the following equation: 


$$
\rho_{m}=\frac{p}{Z R T}
$$

where: i) $p$ is the absolute pressure; ii) $\mathrm{R}$ is the universal gas constant; iii) $\mathrm{T}$ is the absolute temperature.

The calculation method of compressibility factor is critical in NG industries especially for large flow metering plants [19]. In order to assess its reliability, the calculation of the compressibility factor has been carried out also using the ISO 12213-3, AGA NX 19 and AGA NX 19 Mod. standards, which are still used in NG industries.

\section{Results and discussion}

\subsection{Analysis of the thermodynamic properties of H2NG mixtures}

Aimed at evaluating the effects of hydrogen injection in natural gas mixtures, the authors investigated $5 \mathrm{NG}$ mixtures (i.e. the ones without presence of $\mathrm{H}_{2}$ ) used as example calculations in Annex C of ISO 12213-2:2010 [17], as described in Table 2.

Table 2. Molar composition of the investigated gas mixtures.

\begin{tabular}{|l|c|c|c|c|c|}
\hline \multicolumn{1}{|c|}{ Substance } & GAS 1 & GAS 2 & GAS 3 & GAS 5 & GAS 6 \\
\hline Methane, $\mathrm{CH}_{4}$ & 96.50 & 90.70 & 85.90 & 81.20 & 82.60 \\
\hline Ethane, $\mathrm{C}_{2} \mathrm{H}_{6}$ & 1.80 & 4.50 & 8.50 & 4.30 & 3.50 \\
\hline Propane, $\mathrm{C}_{3} \mathrm{H}_{8}$ & 0.45 & 0.84 & 2.30 & 0.90 & 0.75 \\
\hline n-Butane, $\mathrm{n}-\mathrm{C}_{4} \mathrm{H}_{10}$ & 0.10 & 0.15 & 0.35 & 0.15 & 0.12 \\
\hline iso-Butane, iso- $\mathrm{C}_{4} \mathrm{H}_{10}$ & 0.10 & 0.10 & 0.35 & 0.15 & 0.12 \\
\hline n-Pentane, $\mathrm{n}-\mathrm{C}_{5} \mathrm{H}_{12}$ & 0.03 & 0.04 & 0.05 & 0.00 & 0.04 \\
\hline iso-Pentane, iso- $\mathrm{C}_{5} \mathrm{H}_{12}$ & 0.05 & 0.03 & 0.05 & 0.00 & 0.04 \\
\hline n-Hexane, $\mathrm{C}_{6} \mathrm{H}_{14}$ & 0.07 & 0.04 & 0.00 & 0.00 & 0.02 \\
\hline Nitrogen, $\mathrm{N}_{2}$ & 0.30 & 3.10 & 1.00 & 5.70 & 11.70 \\
\hline Carbon dioxide, $\mathrm{CO}_{2}$ & 0.60 & 0.50 & 1.50 & 7.60 & 1.10 \\
\hline
\end{tabular}

In Figure 1 the results of the analyses have been graphically reported. Where available, in the graphs the dashed lines represent the allowable limit according to the related applicable standards and national regulations as below reported:

- relative density and higher heating value [17];

- Wobbe Index [20];

- $\quad$ speed of sound for ultrasonic domestic gas meters [21];

- D $c_{p}$ product for thermal mass gas meters [22]. 


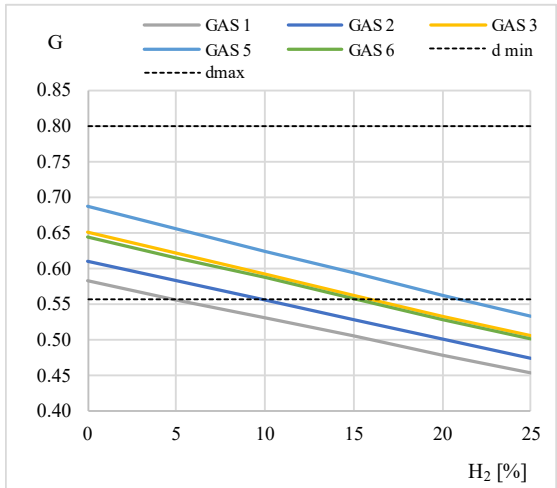

a)

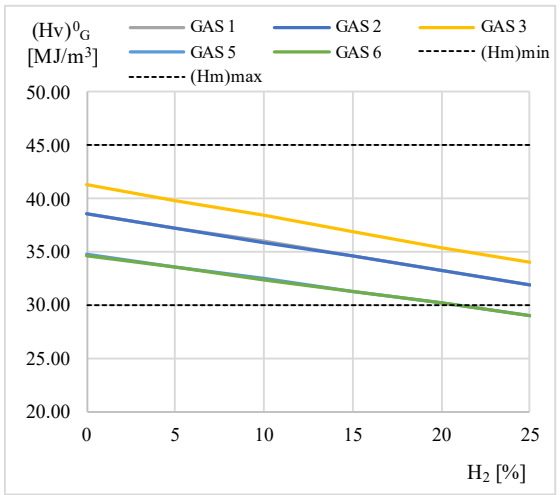

c)

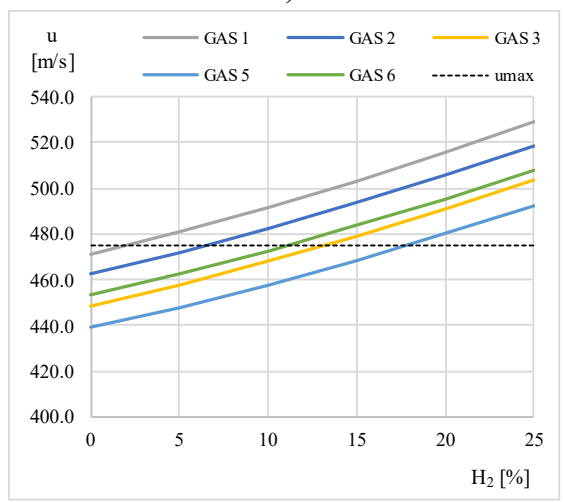

e)

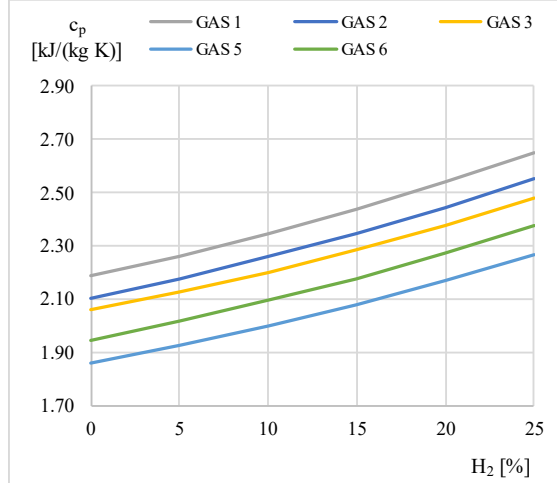

b)

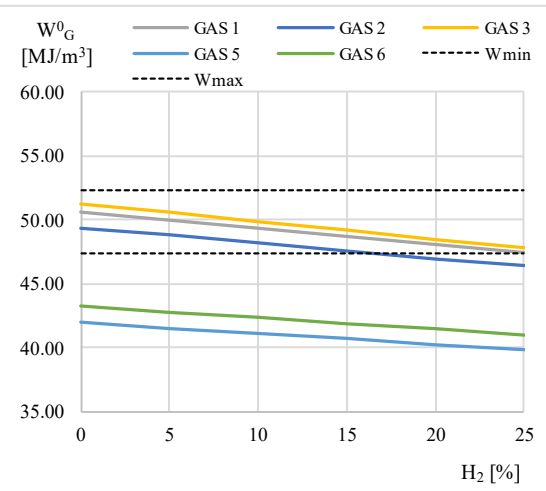

d)

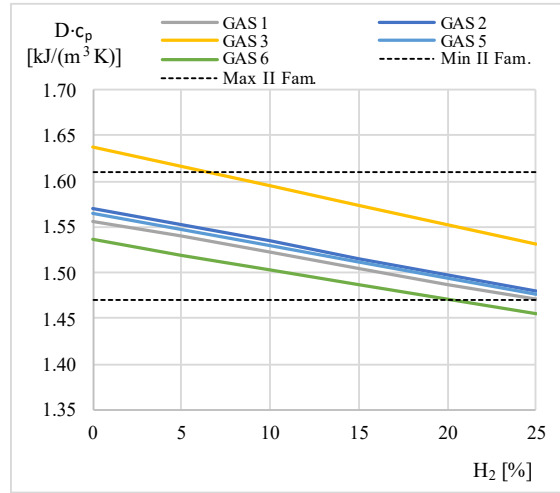

f)

Fig. 1. Trend of thermophysical properties of $\mathrm{H} 2 \mathrm{NG}$ mixtures as a function of the $\mathrm{H}_{2}$ content: a) relative density, b) specific heat capacity, c) higher heating value, d) Wobbe Index, e) speed of sound and f) $\mathrm{D} \cdot \mathrm{c}_{\mathrm{p}}$ product.

From the above reported results, it can be highlighted that:

- the relative density of the $\mathrm{H} 2 \mathrm{NG}$ mixture decreases as the $\mathrm{H}_{2}$ content increases leading to values lower than the corresponding limit EN ISO 12213-2 at about $10 \% \mathrm{H}_{2}$;

- the heat capacity at constant pressure significantly increases as the hydrogen content increases (up to $+21.8 \%$ for Gas 6 at $\mathrm{x}_{\mathrm{H} 2}=25 \%$ ); 
- the higher heating value per volume significantly decreases as the hydrogen content increases (up to $-17.8 \%$ for Gas 3 at $\mathrm{x}_{\mathrm{H} 2}=25 \%$ ) and for investigated gases 5 and 6 it becomes lower than the corresponding limit of EN ISO 12213-2 at $\mathrm{x}_{\mathrm{H} 2}=25 \%$ );

- the Wobbe Index smoothly decreases as the $\mathrm{H}_{2}$ content increase (up to - $6.6 \% \mathrm{x}_{\mathrm{H} 2}=25 \%$ );

- the speed of sound increases up to $12.3 \%$ and it becomes tendentially higher than the accepted limit of $475 \mathrm{~ms}^{-1}$ of the ISO 14236 standard for ultrasonic gas meters even at low $\mathrm{H}_{2}$ contents;

- the $\mathrm{D} \cdot \mathrm{c}_{\mathrm{p}}$ product decreases as the $\mathrm{H}_{2}$ content increases (up to - $6.7 \%$ for Gas 3 ); this can lead to unavoidable drift of the error curve of thermal mass gas meters unless an effective gas recognition system is present with the consequent need for design changes.

\subsection{Analysis of the compressibility factor of $\mathrm{H} 2 \mathrm{NG}$ mixtures}

The effects of hydrogen injection in natural gas mixtures have been also evaluated in terms of accuracy of the compressibility factor measurement. To this aim, a typical NG mixture distributed in Italy has been considered (see Table 3).

Table 3. Molar composition of the investigated gas mixture.

\begin{tabular}{|l|c|}
\hline \multicolumn{1}{|c|}{ Component } & (\% mol/mol) \\
\hline Methane, $\mathrm{CH}_{4}$ & 95.99 \\
\hline Ethane, $\mathrm{C}_{2} \mathrm{H}_{6}$ & 2.292 \\
\hline Propane, $\mathrm{C}_{3} \mathrm{H}_{8}$ & 0.639 \\
\hline n-Butane, $\mathrm{n}-\mathrm{C}_{4} \mathrm{H}_{10}$ & 0.097 \\
\hline iso-Butane, iso- $\mathrm{C}_{4} \mathrm{H}_{10}$ & 0.102 \\
\hline n-Pentane, $\mathrm{n}-\mathrm{C}_{5} \mathrm{H}_{12}$ & 0.012 \\
\hline iso-Pentane, iso- $\mathrm{C}_{5} \mathrm{H}_{12}$ & 0.018 \\
\hline n-Hexane, $\mathrm{C}_{6} \mathrm{H}_{14}$ & 0.012 \\
\hline Nitrogen, $\mathrm{N}_{2}$ & 0.650 \\
\hline Carbon dioxide, $\mathrm{CO}_{2}$ & 0.188 \\
\hline
\end{tabular}

Figure 2 shows the effects of the increase of $\mathrm{H}_{2}$ content up to $25 \%$ in the NG mixture on the compressibility factor Z, calculated employing the ISO 12213-2, ISO 12213-3, AGA NX 19 and AGA NX 19 Mod algorithms. Calculations have been performed at different gas pressures considering a constant gas temperature $\mathrm{T}=15^{\circ} \mathrm{C}$.

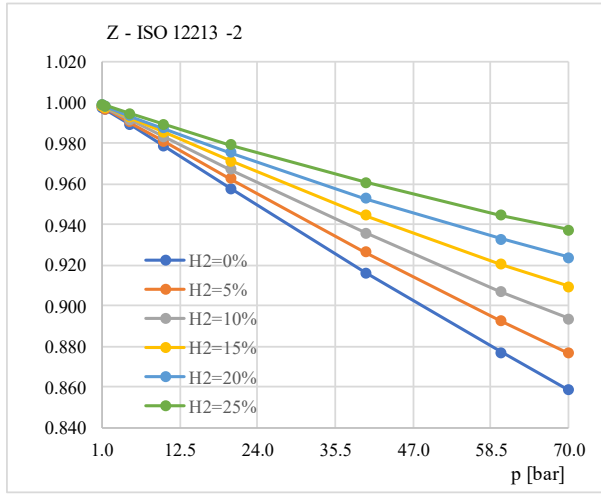

a)

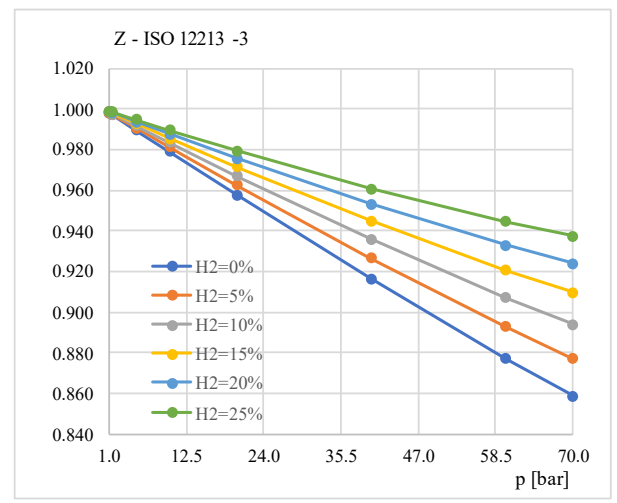

b) 


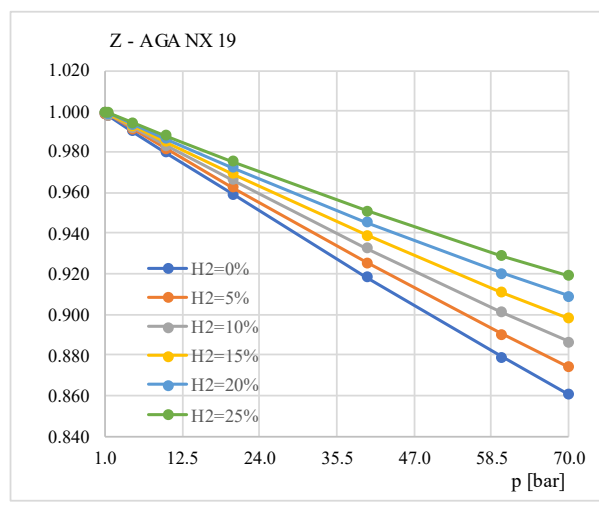

c)

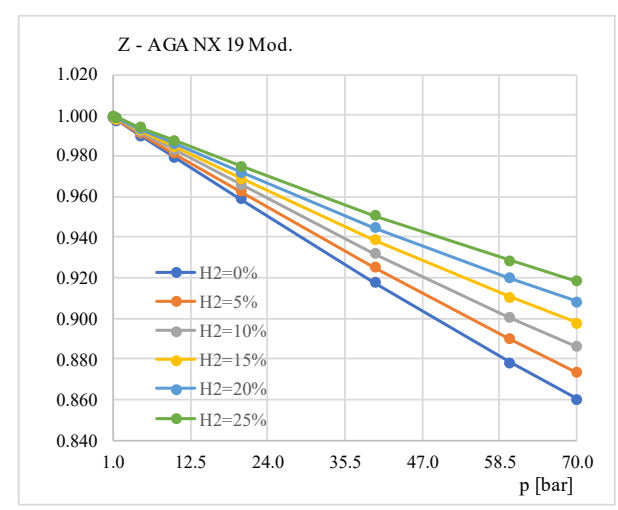

d)

Fig. 2. Trend of compressibility factor, $\mathrm{Z}$, as a function of the $\mathrm{H}_{2}$ content: a) ISO 12213-2, b) ISO 12213-3, c) AGA NX 19 and d) AGA NX 19 Mod..

From the obtained results it can be observed that the compressibility factor increases as $\mathrm{H}_{2}$ content increases. Furthermore, at high pressures $\mathrm{H}_{2}$ content affects the compressibility factor more than at low pressures (e.g. using the ISO 12213-2 standard an increase in the range 0.10 $-0.44 \%$ at 5 bar and $2.1-9.1 \%$ at 70 bar have been found). Moreover, the obtained results show that pressure more significantly influence the compressibility factor at low $\mathrm{H}_{2}$ concentrations.

Finally, the compressibility factor decreases as pressure increases. As for example, a decrease of $\mathrm{Z}$ has been found in the range $0.25-14 \%$ at $\mathrm{H}_{2}=0 \%$ together with at $\mathrm{H}_{2}=25 \%$ a lower decrease in the range $0.05-0.2 \%$ at $\mathrm{H}_{2}=25 \%$.

\section{Conclusions}

The reliability of hydrogen and natural gas mixtures in existing infrastructures (e.g. pipelines, valves, compressor, measuring systems) is a crucial issue the current energy transition in European Union. Injection of hydrogen into natural gas networks, in fact, directly affects thermodynamic properties of the gas itself. As a consequence, changes in the metrological performance especially in terms of volume and gas quality measurements are expected.

In the present paper the change of the main thermo-physical parameters of $\mathrm{H} 2 \mathrm{NG}$, including density, relative density, higher heat value, Wobbe Index, specific heat capacity and sound speed have been analysed when $\mathrm{H}_{2}$ content in the mixture varies up to $25 \%$.

The obtained results show that $\mathrm{H}_{2}$ injection in the NG mixture significantly affects the relative density, heat capacity and higher heating value, whereas the Wobbe Index is smoothly influenced. In particular, the relative density decreases as $\mathrm{H}_{2}$ content increases and for GAS 6 just at $10 \% \mathrm{H}_{2}$ sufficient the corresponding lower limit is exceeded. Similarly, the higher heating value significantly decreases as the $\mathrm{H}_{2}$ content increases. As for example, for gases characterized by a low content of $\mathrm{CH}_{4}$, the higher heating value decreases up to $20 \%$ at $25 \%$ $\mathrm{H}_{2}$ exceeding the lower limit of EN ISO 12213-2.

Furthermore, the $\mathrm{H}_{2}$ concentration considerably affects both the sound speed and $\mathrm{D} \cdot \mathrm{c}_{\mathrm{p}}$ product. In particular, the speed of sound increases up to $12.3 \%$ becoming tendentially higher than the accepted limit of $475 \mathrm{~ms}^{-1}$ of the ISO 14236 standard for ultrasonic gas meters starting from $\mathrm{H}_{2}=5 \%$. On the other hand, the D $\cdot \mathrm{c}_{\mathrm{p}}$ product decreases up to $6.7 \%$ for Gas 3 as the $\mathrm{H}_{2}$ concentration increases. 
The compressibility factor trend as a function of $\mathrm{H} 2$ content has been also investigated basing on the ISO 12213-2, ISO 12213-3, AGA NX 19 and AGA NX 19 Mod. algorithms. The obtained results show the compressibility factor at high metering pressures is higher affected by $\mathrm{H}_{2}$ content than at low pressures. In fact, the compressibility factor evaluated using the ISO 12213-2 standard increases as $\mathrm{H}_{2}$ content increases in the range $0.10-0.44 \%$ at 5 bar, whereas it increases in the range $2.1-9.1 \%$ at 70 bar. Furthermore, gas pressure shows a more significant effect on the compressibility factor at low $\mathrm{H}_{2}$ concentrations.

\section{References}

1. A.A. Stetsenko, S.D. Nedzelsky, V.A. Naumenko, The effect of hydrogen on the physical properties of natural gas and the metrological characteristics of its metering systems, Metrolog. and Instr. (2020) 45-50. https://doi.org/10.33955/23072180(6)2019.45-50.

2. A. Mazza, E. Bompard, G. Chicco, Applications of power to gas technologies in emerging electrical systems, Renewable and Sustainable Energy Reviews. 92 (2018) 794-806. https://doi.org/10.1016/j.rser.2018.04.072.

3. A. Perna, L. Moretti, G. Ficco, G. Spazzafumo, L. Canale, M. Dell'Isola, SNG Generation via Power to Gas Technology: Plant Design and Annual Performance Assessment, Applied Sciences. 10 (2020) 8443. https://doi.org/10.3390/app10238443.

4. Z. labidine Messaoudani, F. Rigas, M.D. Binti Hamid, C.R. Che Hassan, Hazards, safety and knowledge gaps on hydrogen transmission via natural gas grid: A critical review, International Journal of Hydrogen Energy. 41 (2016) 17511-17525. https://doi.org/10.1016/j.ijhydene.2016.07.171.

5. A. Witkowski, A. Rusin, M. Majkut, K. Stolecka, Analysis of compression and transport of the methane/hydrogen mixture in existing natural gas pipelines, International Journal of Pressure Vessels and Piping. 166 (2018) 24-34. https://doi.org/10.1016/j.ijpvp.2018.08.002.

6. DVGW (Hg.): Entwicklung von modularen Konzepten zur Erzeugung, Speicherung und Einspeisung von Wasserstoff und Methan in, (n.d.).

7. H. Iskov, J. Jensen, Field test of hydrogen in the natural gas grid, Amsterdam, 2006. http://www.dgc.eu/sites/default/files/filarkiv/documents/C0605_field_test_hydrogen.p df.

8. J. Dehaeseleer, The effects of injecting hydrogen (renewable gases), (2018). https://easee-gas.eu/uploads/kcFinder/files/20180328-PanelDiscussion-

MARCOGAZ\%20H2Injection.pdf.

9. J. Jaworski, P. Kułaga, T. Blacharski, Study of the Effect of Addition of Hydrogen to Natural Gas on Diaphragm Gas Meters, Energies. $13 \quad$ (2020) 3006. https://doi.org/10.3390/en13113006.

10. J. Jaworski, A. Dudek, Study of the Effects of Changes in Gas Composition as Well as Ambient and Gas Temperature on Errors of Indications of Thermal Gas Meters, Energies. 13 (2020) 5428. https://doi.org/10.3390/en13205428.

11. MARCOGAZ, Overview of test results and regulatory limits for hydrogen admission into existing natural gas infrastructure and end use, (2019). https://www.marcogaz.org/publications-1/documents/.

12. Instytut Nafty i Gazu - Państwowy Instytut Badawczy, M. Łach, Dokładność wyznaczania współczynnika ściśliwości gazu z podwyższoną zawartością wodoru porównanie metod obliczeniowych, NG. $72 \quad$ (2016) 329-338. https://doi.org/10.18668/NG.2016.05.04. 
13. UNI EN ISO 6976:2017 Natural gas - Calculation of calorific values, density, relative density and Wobbe indices from com, (n.d.).

14. AGA REPORT \#10 (2003) Speed of Sound in Natural Gas and Other Related Hydrocarbon Gases, (n.d.).

15. A. K. Coker, Ludwig's Applied Process Design for Chemical and Petrochemical Plants, Elsevier, 2007. https://doi.org/10.1016/B978-0-7506-7766-0.X5000-3.

16. A.K. Coker, E.E. Ludwig, Ludwig's applied process design for chemical and petrochemical plants, 4th ed, Elsevier Gulf Professional Pub, Amsterdam; Boston, 2007.

17. UNI EN ISO 12213-2:2010 Natural gas - Calculation of compression factor Calculation using molar-composition analysis.

18. M. Jaeschke, A.E. Humphreys, Standard GERG virial equation for field use: simplification of the input data requirements for the GERG virial equation; an alternative means of compressibility factor calculation for natural gases and similar mixtures, Als Ms. gedr, VDI-Verl, Düsseldorf, 1992.

19. M. Farzaneh-Gord, B. Mohseni-Gharyehsafa, A. Toikka, I. Zvereva, Sensitivity of natural gas flow measurement to AGA8 or GERG2008 equation of state utilization, Journal of Natural Gas Science and Engineering. 57 (2018) 305-321. https://doi.org/10.1016/j.jngse.2018.07.014.

20. SNAM Rete Gas, Codice di Rete. Allegato 11/A.

21. BS EN 14236:2018 Ultrasonic domestic gas meters.

22. UNI 11625:2016 Contatori di gas - Contatori di gas con elemento di misura massicotermico a circuito capillare. 